\title{
Stakeholders and social influence in a shadow network: implications for transitions toward urban water sustainability in the Colorado River basin
}

\author{
Amber Wutich $^{1}$, Christine DeMyers $^{2}$, Julia C. Bausch $^{3}$, Dave D. White $^{4,5}$ and Abigail Sullivan $^{6}$
}

\begin{abstract}
Shadow networks can play an important role in facilitating transitions toward more sustainable and resilient socialecological systems. Yet, few studies have explored the microdynamics of shadow networks to understand what makes them more or less effective in sustainability transitions. This article examines stakeholder roles and social influence in support of radical innovations over time in a shadow network focused on urban water sustainability in the Colorado River basin. Using qualitative analysis of meeting transcripts and social network analysis, we analyzed the roles of stakeholders from market, government, and scientific sectors in advocating for and influencing other shadow-network members to consider incremental and radical innovations over a 5-year period. The results show that, in our case, stakeholders from the market sector suggested most of the radical innovations. Government-aligned stakeholders mostly supported others' suggestions and facilitated support for niche innovations to become more widespread. Science stakeholders were supportive of others' proposals but were never the source of new ideas for radical innovations; they focused more on interrogating the evidence for and efficacy of others' proposals. These results illustrate how shadow networks can nurture support for radical innovations over time, even when most network members are aligned with the current regime. This research yields new insights about shadow networks in sustainability transitions, and points to the need for more focused analysis of stakeholder roles and social influences within shadow networks to help understand how radical innovations gain support and become better institutionalized.
\end{abstract}

Key Words: Colorado River basin; radical innovation; shadow networks; stakeholder analysis; sustainability transition; water management

\section{INTRODUCTION}

Shadow networks, or informal stakeholder groups who coordinate to address an ecological crisis, are valuable for building more sustainable and resilient social-ecological systems (Gunderson 1999, Olsson et al. 2006, Pelling et al. 2008, Bos et al. 2015). To date, few studies have examined the microdynamics of shadow networks to determine what might make them more or less effective in transitioning social-ecological systems toward sustainability. Drawing on the literature on sustainability transitions and the radical innovations that can stimulate them (Elzen and Wieczorek 2005), we examine stakeholder roles and social influence around radical innovations in a shadow network. In this paper, we focus on the microdynamics of a shadow network that met over a period of nearly five years in the western United States. The shadow network was formed to address serious social and ecological sustainability challenges in the Colorado River basin (Sullivan et al. 2017). Our analysis yields new insights about the dynamics of social influence in a shadow network as it (1) produces knowledge about radical innovations for sustainability transitions over time, (2) enables actors from different stakeholder groups to suggest radical innovations, and (3) provides a platform for social influence among diverse stakeholders who support radical innovations.

\section{LITERATURE REVIEW}

Sustainability transitions

Sustainability transitions are defined as large-scale, nonlinear complex systems changes necessary to resolve major societal challenges (Loorbach et al. 2017). Such transitions can emerge over a period of several decades in four phases: predevelopment, take-off, breakthrough, and stabilization (Grin et al. 2010). In predevelopment, the system is in a state of dynamic equilibrium. During take-off, the system begins to change. In breakthrough, visible structural changes occur as accumulated socio-cultural, economic, ecological, and institutional changes react to each other, along with collective learning and knowledge diffusion. Finally, a new dynamic equilibrium emerges in the stabilization phase (Rotmans et al. 2001).

Elzen and Wieczorek (2005) distinguish between two types of innovations in transitions: (1) incremental innovations and (2) radical innovations. Incremental innovations are shifts that rely on existing technologies, infrastructures, and systems and do not involve systemic change. Radical innovations refer to systemic (technical and socio-cultural) changes (Elzen and Wieczorek 2005). The transitions literature argues that radical innovations are necessary to achieve sustainability (e.g., Loorbach et al. 2017). Although the radical innovations concept is commonly used in the transitions literature, it is similar to the concept of transformational adaptation, which is more commonly used in the climate change adaptation literature (Pelling 2010, Kates et al. 2012, Taylor 2014).

Radical innovations typically emerge from specialized niches (representing innovations, novelties, or alternatives), and can then be adopted or propagated to the wider society (Geels 2002, Markard et al. 2012, Loorbach et al. 2017). Local government and governance actors can be important for enabling the creation of niches, and the uptake of niche innovations is an especially important moment in sustainability transitions (Fischer and Newig 2016). Recent scholarship in sustainability transitions has examined how power, politics, and special interests facilitate or

${ }^{1}$ School of Human Evolution and Social Change, Arizona State University, Tempe, AZ, USA, ${ }^{2}$ The Water Institute of the Gulf, Baton Rouge, LA, USA, ${ }^{3}$ Morrison Institute for Public Policy, Arizona State University, Phoenix, AZ, USA, ${ }^{4}$ Decision Center for a Desert City, ${ }^{5}$ School of Community Resources and Development, Arizona State University, Tempe, AZ, USA, ${ }^{6}$ Environmental Resilience Institute, Indiana University, Bloomington, IN, USA 
impede this process (e.g., Avelino and Wittmayer 2016, Avelino and Grin 2017). This scholarship highlights the importance of understanding how powerful actors support or oppose sustainability transitions (Fischer and Newig 2016), as such support can be crucial to creating the conditions that support radical innovation in niches and their diffusion throughout society.

\section{Role of shadow networks in sustainability transitions}

Shadow networks are widely recognized as important for facilitating adaptive governance of social-ecological systems (Gunderson 1999, Pahl-Wostl 2009). They can be defined as informal networks of people who are working both inside and outside of the dominant system, who facilitate information flows, create nodes of expertise, identify knowledge gaps, engage in social learning, and explore alternatives that could replace the dominant system when there is a window of opportunity (Olsson et al. 2006, Westley et al. 2011). Shadow networks evolve over time and provide important opportunities for the incremental transformation of social-ecological systems (Olsson et al. 2006).

Shadow networks can act as coalitions capable of advancing radical innovations and sustainability transitions. Shadow networks have a number of specific functions that can be valuable for sustainability transitions. First, they can identify problems and incubate new ideas and approaches (Westley et al. 2011). Second, they can provide key knowledge and opportunities for social learning through experiments in transitions (Brown et al. 2013). Third, they can generate socio-political capital (Bos and Brown 2012). Fourth, they can push local solutions into national decision-making contexts (Gelcich et al. 2010, Westley et al. 2013, Olsson et al. 2014). In the realm of urban water transitions, specifically, shadow networks can be valuable for creating coalitions to generate radical change (Bos et al. 2015, de Haan et al. 2015).

In sum, shadow networks can be crucial to the take-off phase of sustainability transitions because they can nurture niche innovations, cultivate collaborative problem-solving, and mobilize resources (Loorbach 2010, Brundiers and Eakin 2018). Their value is dual: they can enable "short-term innovation" while at the same time providing a space for "long-term sustainability visions" that can help produce sustainability transitions (Loorbach 2010:163). One important element of shadow network performance is members' capacity to interact in ways that can produce support for radical innovations (Bos et al. 2015).

\section{Stakeholder dynamics in sustainability transitions and shadow networks}

Despite the potential importance of shadow networks in facilitating sustainability transitions, relatively few studies in the field of sustainability science have examined stakeholder dynamics and social influence in shadow networks (cf. Brown et al. 2016). However, the broader literature on actors and agency in sustainability transitions provides some guidance on what kinds of stakeholders might facilitate transformational changes (Avelino and Wittmayer 2016, Loorbach et al. 2017, Wittmayer et al. 2017). We infer that the general dynamics described in this literature might pertain to shadow networks specifically.

Research indicates that innovative strategies are most likely to come from "niche actors" (Fischer and Newig 2016) or "frontrunners" (Loorbach 2010), rather than the "regime" (or dominant order in a social system, following Loorbach et al. 2017). These are people outside of the incumbent regime, who distribute new radical innovations; these innovations can be adapted to the incumbent regime or can replace it. In contrast, "regime actors" are those who are aligned with existing power structures and may be more likely to resist sustainability transitions (Rock et al. 2009, Farla et al. 2012, Fischer and Newig 2016). Even so, regime actors can support niche innovations in important ways, including facilitating their uptake (Fischer and Newig 2016). For these reasons, both niche and regime actors can play important roles in sustainability transitions (Loorbach 2010). Recent work has drawn attention to the importance of connectors and supporters as transformative actors (de Haan and Rotmans 2018).

The literature on actors in sustainability transitions proposes that various stakeholders may occupy complex, shifting roles over time (Geels 2012, Avelino and Wittmayer 2016, Fischer and Newig 2016, Wittmayer et al. 2017). Scholarship on sustainability transitions has identified four stakeholder types: actors from government, science, market, and civil society (Grin et al. 2010, Geels 2012). In this paper, we focus on the government, science, and market actors because of the composition of the shadow network in our focal case (discussed later). Stakeholders from market, government, and science sectors can drive radical innovations by identifying, experimenting with, and adopting sustainability strategies within alternative or protected niches, as well as by supporting and spreading their adoption within regimes (Loorbach 2010, Loorbach et al. 2017; see Fischer and Newig 2016 for an extensive review of this literature). In some empirical cases of sustainability transitions, market stakeholders, including members of the business community, have been important sources of radical innovation on technologies and other aspects of sustainable lifestyles (e.g., Boons et al. 2013). Government stakeholders have played an important role in encouraging experimentation around radical innovations and supporting promising niches (e.g., Elzen and Wieczorek 2005, Foxon et al. 2010). Stakeholders from science and technology sectors can create radical innovations, whether in the realm of technology or socioeconomics, and importantly can experiment with and test the efficacy of these innovations (e.g., Lang et al. 2012).

To move this literature forward, there is a need for more empirical research focused on specific social-ecological systems, resource sectors, and sustainability transition processes (Loorbach et al. 2017). Furthermore, a common critique of transition research is that it suffers from inadequate attention issues of agency and poor conceptualizations of actors (Markard et al. 2012) and our study addresses this limitation. In this analysis, we examine the roles of stakeholders from market, government, and scientific sectors, over time, in supporting radical innovations and influencing other shadow network members to consider supporting them. Specifically, we focus on describing three core phenomena:

1. The degree to which members of the shadow network support radical innovations (vs. incremental innovations) over time.

2. How social influence develops among stakeholders within the shadow network when a radical innovation is introduced. 
3. How specific innovations (incremental and radical) differ across stakeholders from different sectors (market, government, or science).

\section{RESEARCH SETTING}

This research was conducted in the context of a shadow network focused on risks to urban water sustainability in the Colorado River basin of the western United States. The Colorado is arguably the most overallocated and heavily regulated transboundary river system in the world (Christensen et al. 2004, Hundley 2009, Woodhouse et al. 2010). Agricultural demand and urban population growth are increasingly stressing water supplies for people and the environment in this water-scarce region. Global climate change has already caused higher average temperatures in the region and significant additional warming is projected by midcentury, which will diminish freshwater supplies and increase water demands (Gonzalez et al. 2018). The recent drought in the region is the most extreme in 100 years and among the worst of the last 1200 years (USBOR 2018) and is consistent with projections for increased risk of multidecadal "megadroughts" (Cook et al. 2015, Ault et al. 2016). Urban areas dependent on Colorado River water, such as Phoenix, Denver, Las Vegas, and Los Angeles, are being forced to adapt to these rapid social and environmental changes and develop innovative water management strategies.

Urban water governance regimes in the Colorado River basin cities have undergone several transitions toward sustainability in the past (Sullivan et al. 2017), but analysts argue that further radical innovation is needed to overcome new challenges and deal with the myriad developments affecting water systems in an era of deep uncertainty and climate change (Kates et al. 2012, Gober 2013, 2018). The dominant order in the contemporary sociotechnical regime for urban water governance in the region is characterized by a centralized approach to water management with bureaucratic decision-making processes. Water policy, especially at the state level, is heavily influenced by agricultural and private sector housing development interests. There is an historical reliance on grey infrastructure informed by physical engineering knowledge systems, and culture of supply-side solutions. This stability of the regime is supported by path dependence, sunk costs, technological lock-in, and the lack of incentives for innovation (Larson et al. 2013, Sullivan et al. 2017). The policy response to drought and climate change risks has suffered from power imbalances, lack of inclusive and transparent decision making, lack of urgency, distrust, and short-term thinking (Sullivan et al. 2019).

The stability of the dominant regime is susceptible to disruption by exogenous landscape-level developments, e.g., global climate change, as well as networks of actors who offer disruptive innovations in technology, institutional and organizational design, economic strategies, and changing socio-cultural preferences (Loorbach et al. 2017). For instance, recent examples of disruptive changes promoted by niche actors include aggressive demand management, widespread rainwater harvesting, direct potable reuse of recycled wastewater, renewable energy for water treatment and transport, emphasis on local water sources, and moves toward decentralized and inclusive decision making (White et al. 2019).
Against the backdrop of these challenges, a shadow network composed of stakeholders from government, science, and market sectors coalesced in 2013, as an outgrowth of a larger, established science-policy research network. The shadow network was sparked as organizers and participants recognized that small sets of actors were developing niche innovations to address critical urban water sustainability risks but these innovations were disconnected and no regional forum existed for systematic review and evaluation of the potential to scale-up local solutions to address regional challenges. The organizers engaged in "boundary work" to provide a neutral convening space to provide the network an opportunity to discuss issues in an environment sheltered from political and regulatory pressures in other settings, which can hinder discussions (Quay et al. 2013).

The shadow network met formally in organized multiday sessions three times over a nearly five-year period. The network was initiated in late 2011 and has had five meetings as of 2019. The research team has been involved in the formation and facilitation of the network from the beginning and was able to arrange for audio and video recording of three meetings. The network was facilitated by smaller subsets of actors, or steering committees, who met informally on a recurring basis throughout the period covered in our research. These steering committees periodically identified emerging topics of water governance, identified actors actively engaged in research and program development related to these topics, and organized events to invite these actors to discuss their work. The overarching goal of the network was to understand and support research of urban water governance for emerging topics in technology, science, industry, and markets and user preferences. A key objective was to stimulate collaborative research and experimentation among government, market, and scientific actors to promote social learning, develop and evaluate evidence-supported sustainability transition strategies, and support the movement of disruptive niche innovations to regimes. The purpose of the formal meetings was to share research and practitioner knowledge about the complex challenges and opportunities associated with changing urban water demand in social-ecological systems. Given these goals, participants were recruited based on their active involvement in urban water sustainability research, policy implementation, experimentation, and evaluation. The shadow network included actors working within the dominant regime for urban water governance as well as niche actors; the key criterion being that regime actors must be actively developing innovations within their organizations or cooperating with actors in niches working on disruptive solutions.

\section{METHODS}

\section{Data collection}

This study examines data collected during three meetings of the shadow network, which occurred in 18-month intervals over a five-year period. Meetings were held in Colorado and Arizona, and discussion of local challenges was common. Each meeting was attended by about 20 stakeholders from the Colorado River basin. Because participation in the shadow network is fluid, some stakeholders were only present for one or two meetings. This analysis focuses on 43 stakeholders from the Colorado River basin: 17 from the market sector; 14 from the government sector; 12 from the science sector (Table 1). The number of stakeholders 
Table 1. Shadow network members, by stakeholder sector.

\begin{tabular}{lcccc}
\hline \hline & Market & Government & Science & Total \\
\hline Total & 17 & 14 & 12 & 43 \\
number & & & & \\
Meeting 1 & 8 & 6 & 5 & 19 \\
Meeting 2 & 7 & 4 & 7 & 18 \\
Meeting 3 & 8 & 9 & 4 & 21 \\
\hline
\end{tabular}

and meetings meets the minimum likely needed for data saturation in thematic analysis (Guest et al. 2006, 2017).

Our data were collected using participant-observation and audio/ video recordings from the shadow network meetings. In addition, coauthor D. D. White is a long-term member of the shadow network and provides historical depth and context to our observations; he also provides insights about the nature of informal and unplanned interactions among shadow network members. Our final datasets contained detailed field notes based on participant-observation of the formal meeting sessions, transcriptions of verbal interactions during the formal meeting sessions, and archival records, e.g., emails, participant lists, contributed by D. D. White that shed light on the shadow network's formation and composition.

The general structure of the meetings remained consistent across the 5-year period. Each meeting was designed to address four to six pertinent topics related to urban water demand. These topics were organized into sessions that all stakeholders were evenly divided across. Each stakeholder, in this analysis, was a presenter at the meeting. All stakeholders were present, in the same room, for all sessions and each session concluded with a group-wide discussion.

The format of the meetings mirrors our data analysis methods outlined in the next session. Meeting presentations were analyzed primarily for whether or not a stakeholder had implemented an incremental or radical innovation. Group-wide discussions were analyzed primarily for social influence around the incremental or radical innovations that were previously presented during the session. The organization of these meetings allowed us to delineate which stakeholders had implemented incremental and radical innovations and which stakeholders were influenced by, and supportive of, those solutions during discussions.

\section{Data analysis}

To investigate the three core phenomena, we coded and analyzed data from field notes and transcriptions of the shadow network meetings. The data were systematically coded to identify the following: implementation of "radical innovations," implementation of "incremental innovations," and support for incremental versus radical innovations, which we coded as "social influence" using the coding methods outlined in Bernard et al. (2016). Following Elzen and Wieczorek (2005), we defined radical and incremental innovations in the context of urban water sustainability (Sullivan et al. 2017).

We focused on stakeholders' implementation of and support for solutions that have the potential to lead to a sustainability transition. We did not measure sustainability transitions themselves or the efficacy or impact of certain water demand innovations. In our study, incremental versus radical water demand innovations were coded for based upon specific criteria related to the innovation's potential for impact and the scale of that impact.

To be coded for, stakeholder's verbal statements about radical or incremental innovations needed to have already been implemented and the scale of influence of the innovation needed to be stated. Our distinction between radical versus incremental innovations was focused on the scale of water demand reductions: radical innovations needed to have potential impact the scale of the municipality (as stated by the stakeholder) whereas incremental innovations could occur at scales as small as a change in water use technology for an entire house or a building.

Our code definition for "radical innovation" was as follows: an innovation in which "the social-ecological and/or socio-technical system (and its governance regime) in question has the potential to be significantly altered, including not only infrastructures and technologies, but also practices, interactions, communications, rules, laws, concepts, and values." There were two important inclusion criteria for a speaking turn to be coded as a radical innovation: (1) the speaker stated that the innovation was already implemented, that is, the innovation was not proposed or theoretical, and (2) the speaker stated that the impact of the innovation could be measured in water demand reductions at the municipal scale. These inclusion criteria allowed the coders to judge that the innovation had the potential to radically alter the status quo water management system.

Incremental innovations were coded for using a complementary set of inclusion criteria: (1) the speaker stated that the innovation was already implemented, and (2) the speaker did not state that the impact of the innovation was on the municipal scale. The typical exemplar, in our codebook, of "incremental innovations" is the implementation of a singular technology on one, or a few buildings or residences (examples such as this indicate, again, that the innovation had already occurred and that the scale of water demand reductions was not at the level of the municipality). An atypical exemplar also emerged when coding the innovations that the science stakeholder group had implemented: implementation of use-inspired research and development, or research directed toward improvements in existing urban water sustainability efforts.

The incremental versus radical innovation codes, in sum, are codes that we applied to the transcripts based upon the specific criteria noted above. Stakeholders, therefore, did not have to explicitly state that, or label, their innovations as incremental or radical for us to apply the code to their portion of the transcript; stakeholders only needed to fulfill the codebook definition for either of these two codes.

In addition, we created a social influence code to capture the process in each conversation about radical innovations. During these conversations we coded for social influence during instances in which a stakeholder supported an innovation that was implemented by a different stakeholder. We defined social influence as positive statements that initiate collaborations or 
otherwise increase group support for a radical innovation, e.g., expression of interest, request for information, or invitation to collaborate. The codes were applied using a consensus-based process (Forman and Damschroder 2007), in which two coders discussed and resolved any disagreements in their applications of the code.

The coded data were then analyzed in three ways. First, we coded each unique incremental and radical innovation that was stated to be implemented and disaggregated these by time, i.e., Meeting 1, 2, 3, and stakeholder category, i.e., market, stakeholder, science. Second, we reanalyzed the coded text to provide descriptive themes, following the methods of Bernard et al. (2016). This analysis yielded a list of thematic categories that describe the types of innovations stakeholders supported, informed by the framework developed by Quay and colleagues (2017). Third, for each discussion of a radical innovation with associated video data and transcripts, we conducted social network analysis to assist in our exploration and interpretation of the coded social influence data. Using the social influence data, we created a person-byperson similarity matrix where each cell captures the presence/ absence of directional influence. We then performed one-mode social network analysis using UCINET software. We used the social network visualizations to assist with our interpretation of the social influence dynamics captured in transcripts in which stakeholders advocated for a radical innovation.

We coded the above themes to understand three core phenomena: the presence of supportive discussions for incremental and radical innovations over time (Table 2), the presence of social influence during those discussions (Fig. 1), and the presence of specific types of incremental and radical innovations that were implemented across stakeholder groups (Table 3). Subsequently, in Table 2, we present a count of the number of unique supportive discussions around innovations. In Figure 1, we present the quality of influence that a supportive discussion around a radical innovation can have. In Table 3 we emphasize the difference in type (rather than quantity), and difference in presence, of incremental/radical innovations across stakeholder groups.

\section{RESULTS}

The shadow network produced more supportive discussions of radical innovations over time

To assess the extent to which the shadow network supported radical innovations, we counted the number of times that supportive discussions emerged around incremental and radical innovations in each shadow network meeting. This enables us to assess whether supportive discussions around radical innovations increased over time.

Our data indicate that the shadow network was successful in generating an increasing number of supportive discussions of innovations over the course of three meetings. In the first meeting, more presentation topics were dedicated to discussing the water sustainability challenges and the position roles of the various participants. While this first meeting did not generate any supportive discussions of radical innovations, it did generate some supportive discussions around incremental solutions.

The second meeting generated supportive discussions around incremental innovations only slightly more often than in the previous meeting (Table 2). Significantly, this second meeting marks the point at which the shadow network first showed supportive discussions around radical innovations.

Table 2. Supportive discussions around incremental and radical innovations, over time.

\begin{tabular}{ccc}
\hline \hline Meeting & Incremental innovations & Radical innovations \\
\hline 1 & 5 & 0 \\
2 & 6 & 2 \\
3 & 24 & 4 \\
\hline
\end{tabular}

In the third meeting, the presence of supportive discussions of all innovations increased (Table 2). Supportive discussions around incremental innovations took off, with a large number of related discussions recorded. In contrast, the number of supportive discussions around radical innovations increased, but slowly. Based on these findings, our analysis enables us to cautiously conclude that the shadow network did appear to produce more supportive discussions of all innovations, including radical innovations, over time.

\section{Market stakeholders and, to a lesser extent, government} stakeholders were most likely to advocate for radical innovations All stakeholder groups supported (Table 2) and implemented (Table 3) incremental innovations. Radical innovations were implemented by market stakeholders and government stakeholders (Table 3), and supported by all stakeholder groups in the final two workshops (Table 2). Although the science stakeholders did not directly implement radical innovations, they were later positively influenced to support them (Fig. 1). Across stakeholder groups, there was clear variability in the kinds of innovations that were salient and unique to that group.

\section{Market stakeholders}

The primary incremental innovations that market stakeholders implemented were watering restrictions imposed on turf grass lawns. Unique to market stakeholders' approach was their implementation of "peak use" water use restrictions. For instance, stakeholders explained that restricting water use on turf grass lawns during the times where water use is high caused decreases of overall water demand and high-time water use in Denver. In addition, stakeholders asserted that social norms are changing in the Denver area, in the sense that the "new normal" for watering turf grass lawns has become three days out of the week. Also unique to the market stakeholders' incremental innovations was their implementation of native landscaping, such as low water use and drought-resistant shrubs.

Stakeholders from the market sector implemented radical innovations, such as novel combinations of: new rate structures and rate designs, new approaches to metering, green infrastructure, infrastructure to store/treat/deliver water, waterefficient retrofit technologies, swimming pool restrictions, and education campaigns. In many cases, innovations that could, if implemented by themselves, be coded as incremental, e.g., education campaigns, ended up being coded as radical. This is because the innovation was part of a bundle of innovations that, the stakeholder stated, produced water demand reductions that could be measured at the municipal scale. Solutions that were 
Table 3. Thematic categorization of incremental and radical innovations, by stakeholder sector. Bolded innovations were most salient among stakeholders in each sector. Italicized innovations were unique to stakeholders in each sector. AMR/AMI, Automatic Meter Reading/Advanced Metering Infrastructure.

\begin{tabular}{|c|c|c|c|}
\hline & Market & Government & Science \\
\hline $\begin{array}{l}\text { Incremental } \\
\text { Innovations }\end{array}$ & $\begin{array}{l}\text { Turf watering restrictions; } \\
\text { Native landscaping; } \\
\text { Incentives/subsidies; } \\
\text { Policy; } \\
\text { Education campaigns (e.g., general } \\
\text { public conservation campaign); } \\
\text { Land use planning/development; } \\
\text { Turf removal/xeriscaping; } \\
\text { Water efficient retrofit/technology; } \\
\text { Water demand forecasting models; } \\
\text { Research; }\end{array}$ & $\begin{array}{l}\text { Education campaigns (e.g., general public } \\
\text { conservation campaign); } \\
\text { Incentives/subsidies; } \\
\text { Water demand forecasting models; } \\
\text { Turf watering restrictions; } \\
\text { Land use planning/development; } \\
\text { Water audits; } \\
\text { AMR/AMI; } \\
\text { Online databases; } \\
\text { Climate commitment/resilience strategy } \\
\text { plan; } \\
\text { Advertisements; } \\
\text { Policy; } \\
\text { Water efficient retrofits/technology; } \\
\text { New homes/units; } \\
\text { Turf removal/xeriscaping; }\end{array}$ & $\begin{array}{l}\text { Research; } \\
\text { Policy; } \\
\text { Behavior change; } \\
\text { New homes/units; } \\
\text { Turf watering restrictions; } \\
\text { Water demand forecasting models; } \\
\text { Land use planning/development; }\end{array}$ \\
\hline $\begin{array}{l}\text { Radical } \\
\text { Innovations }\end{array}$ & $\begin{array}{l}\text { Education campaigns (e.g., training new } \\
\text { homeowners about how to use innovative } \\
\text { home technologies to radically conserve } \\
\text { water); } \\
\text { Swimming pool restrictions; } \\
\text { New rate structure/rate design; } \\
\text { Infrastructure to store/treat/deliver water; } \\
\text { Green infrastructure; } \\
\text { Metering; } \\
\text { Water efficient retrofit/technology; } \\
\text { Policy; }\end{array}$ & $\begin{array}{l}\text { Water budget; } \\
\text { Land use planning; } \\
\text { Policy; }\end{array}$ & \\
\hline
\end{tabular}

implemented in a bundle, or as a suite of technical, behavioral, cultural, and other innovations, were discussed in tandem with municipal-scale influence. In this example, for instance, a stakeholder from the market sector introduced a new kind of urban housing development:

Demand reduction comes before development.
Conservation, in my opinion, comes after. Here in
[location in Colorado, there is a] new development ... the
first community in Colorado, permitted, under state law
for rainwater harvesting ... Bottom line is, in the county,
this development was approved with a record never seen
before low, single-family-equivalent water use ... they're
down to almost two-thirds less, so a third of that amount
[of water typically consumed in other communities]. - M3

In this example, a large number of individual innovations were combined in the implementation of the new housing development. For instance, new homeowners received an education kit that helped them understand how to use innovative home technologies to radically conserve water. Each innovation, if implemented alone, would be incremental. However, when implemented together in a newly developed community, the combination of numerous innovations produced a change in the standard for residential water use for the entire municipality. In the context of this shadow network, stakeholders from the market sector seemingly had a unique opportunity to develop, experiment with, and promote social learning around radical innovations.
Government stakeholders

Stakeholders from the government sector implemented a range of mainly incremental innovations. Here we give a few examples of government stakeholders' incremental solutions to illustrate some major thematic categories. In terms of education campaigns, one example was public education on droughtfriendly landscaping in Colorado. For incentives and subsidies, an Arizona stakeholder supported a conservation program that allocates rebates for greywater systems, rainwater harvesting, commercial multifamily irrigation systems, and water efficient toilets and urinals. In terms of water audits, these were supported as tools to detect (and help prevent) leaks or wasted water in the supply-demand process. Automatic meter reading and infrastructure, as a final example from Colorado, was supported to collect information on real-time water use data and enabling water conservation efforts.

In the context of radical innovations, the government stakeholders also had experience with implementing them. During the course of the meetings, however, they were more likely to express their support for innovations from market stakeholders. For example, a stakeholder from the government sector, in response to M3 (previous quote above) said the following:

I love the [new development] concept, I would like to bring that to the level of individual developments within the city and say "here's your water budget, you show me some ways that you can meet that water budget." ... I would love to get other people to be creative to solve these 
issues for us or with us. And I would really like to bring that into, we talked about, development fees ... I think there will be unforeseen consequences, always. But I have a lot of faith in the future, I have a lot of faith that technology will help us and that people's creativity will help us. - G3

This stakeholder was speaking both from previous experience in a different city and from supporting change in the city that he lived in. He described how a water budget places a limit on water withdrawals for zones in a city. In his previous experience, this solution involved a significant, and unexpected, alteration to the total water use in his city; for this reason, his previous experience with implementing water budgets was coded as a radical innovation.

As quoted above, this government stakeholder (G3) was also influenced by the radical solution from M3. G3 spoke of bringing a water budget to his current city by using techniques that were inspired by the project that M3 implemented. He spoke of building consensus in his city council and coordinating with land use planners and other stakeholder groups that do not usually work with water managers, to plan developments with strict limits on total water usage. In this case, the government stakeholder not only implemented a radical innovation, but also envisioned enacting a process to develop broad support for radical innovations.

\section{Science stakeholders}

Stakeholders from the science sector implemented primarily policy and research-related incremental innovations. Examples included the use of campus facilities to install water efficient technology to study changes in water use; the creation of a watersustainable design standard for new infrastructure and land use planning; and the use of water demand forecasting models to predict future water use. These innovations were coded as incremental because they did not directly result in municipal-scale water use reductions, or water use reductions on any scale, however, they were directed at providing guidance to improve existing water sustainability efforts.

Unique to this group, and their research, was their direct targeting of behavior changes. Research-related incremental innovations primarily focused on behavioral changes, particularly in Boulder, Colorado and in Phoenix, Arizona. Researchers used campuses and several city-wide outreach efforts to study behavior changes in water usage over time. For example, one stakeholder from the science sector said the following:

[W]e focus a lot on behavior, for example the effectiveness of education efforts on water use. We also look at cultural factors: how landscaping within neighborhoods and conservation don't always coincide. We also look at what the symbolism of water conserving means within our society particularly here in Phoenix. S8

Notably, stakeholders from the science sector often viewed incremental and radical innovations, implemented by the other two stakeholder groups, as objects of study. Contributions from science stakeholders in some cases centered on probing to determine the efficacy of radical innovations, asking "who is actually doing the monitoring?" and opining "I hope that there's a neutral third party doing the evaluation." Although these stakeholders made supportive comments, their contributions were often focused on evaluating the evidence base for and efficacy of proposed innovations.

\section{Complex social influence dynamics shaped support for radical} innovations in the shadow network

To illustrate social influence processes and the role of different stakeholders, we present an in-depth analysis of a supportive discussion as it developed around a radical innovation. The exemplar we chose is the one introduced by the market stakeholder in the section above, a new housing development in Colorado. Because this development significantly alters the social-technical system (including infrastructure, technology, practices, and cultural aspects) and conservation outcomes, we classify it as a radical innovation. Additionally, because this is a niche innovation with the potential to move to regimes, we identify it as being relevant to understanding the dynamics of "take-off" in a possible sustainability transition.

The social network shows the flow of positive influence in the discussion around this radical innovation in the shadow network as a whole. In Figure 1, the two main hubs of influence are market stakeholder M3 and government stakeholder G3. The radical innovation was introduced by M3, and largely supported by G3 (as well as G8, M4, and S11). M3 positively influenced eight people, including G3, who subsequently positively influenced three people. For instance, an arrow pointing from S1 to M3 indicates that M3 influenced $\mathrm{S} 1$. Each arrow indicates an expression of interest in implementing the radical innovation, question about how to execute the radical innovation, or an invitation to do collaborative work around the radical innovation.

Fig. 1. Social network depicting social influence among stakeholders in a discussion of a radical innovation. Nodes are labeled to indicate stakeholder group: $\mathrm{M}=$ market; $\mathrm{G}=$ government; $\mathrm{S}=$ science. Arrows indicate social influence.

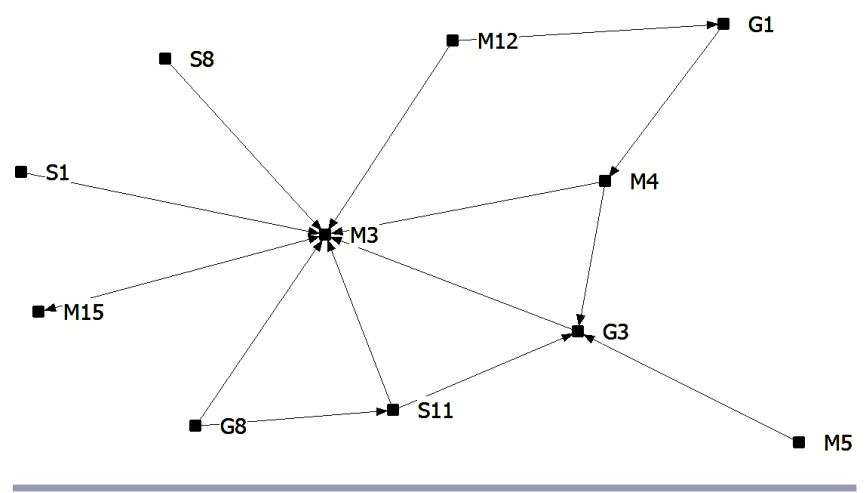

To illustrate a small part of this process, we present a partial transcript:

M3: They're using rainwater harvesting, indoor use reductions...advanced metering and billing...smart meters...real time control. And the rate structure...really sends the price signal to change behavior... And last but not least, true cost impact fees. 
M2: So much for affordable housing.

[laughter]

M3: Uh, that's it. We think this trend is going to continue.

S8: Excellent.

[applause]

S8: You're my model now.

Here, the market stakeholder (M3) acknowledged possible critiques of the evidence base (anticipating comments that did come later from a science stakeholder). A market stakeholder (M2) then expressed skepticism about the affordability of the radical innovation. The first market stakeholder (M3) responded by asserting that a move from niche to regime is likely. A science (S8) stakeholder stepped in and showed support for the radical innovation, prompting applause from the group, and voiced an interest in supporting this niche innovation. Later, a government stakeholder (G3), quoted in the "government stakeholders" section, took up the work of advocating more fully for moving the radical innovation from niche to regime. This exemplar transcript demonstrates the complex social influence dynamics at play around the introduction of a radical innovation to the shadow network.

\section{DISCUSSION AND CONCLUSIONS}

This study examined the role of a shadow network in implementing and supporting radical innovations around urban water sustainability challenges in the Colorado River Basin. One goal was to understand the extent to which support for radical innovations, or those that can help precipitate a sustainability transition, develop over time. Our findings make a unique contribution to the literature by demonstrating how shadow networks can support radical innovations. Specifically, in this case, it took years of interactions and extensive discussion for stakeholders to show substantial support for just a handful of radical innovations. Our study, like those of Bos et al. (2015) and De Haan et al. (2015), suggests that shadow networks may facilitate support for sustainability transitions around urban water management.

The other goals of our study were to understand how social influence around radical innovations develops among different stakeholder groups and the ways that specific types of incremental versus radical innovations differ across stakeholder groups. In our case, stakeholders aligned with the market sector implemented most of the radical innovations in the shadow network. In our context, it appears that market sector actors may be reacting to changing market demands and user preferences, including preference for higher urban residential density and green living, which functionally translate into lower water demands. In the competitive market place for new residential development in the region (in the context of rapid population growth and strong housing demand), some market stakeholders appear to be promoting radical innovations that also have the advantage of differentiating their product and getting ahead of expected market trends. Fischer and Newig (2016:7) found that "initiatives toward transitions mostly depend on business communities and on civil society" and our work adds to this literature by illustrating the role market-aligned stakeholders play in a shadow network promoting for transitions around urban water management.
Government-aligned stakeholders were also active in implementing radical innovations, but most of their influence was focused on supporting the radical innovations of others and facilitating the movement of these radical innovations from niche to regime. Our work highlights the pivotal role of stakeholders from the government sector in exerting social influence in favor of radical innovations. Governance in sustainability transitions is very complex and laden in conflicts around politics and interests (Loorbach 2010), but our case illustrates how shadow networks can develop over time in ways that nurture increasing support for innovations. In doing so, our research may be useful to those seeking to engage stakeholders from the government sector in transition management.

Stakeholders from the science sector, in our study, implemented and supported incremental solutions and only supported radical innovations. In our findings, science-sector stakeholders did not implement radical innovations themselves. In many cases, science stakeholders saw their role as contributing rigorous interrogation of the evidence base for and efficacy of radical innovations being discussed. This aligns well with the findings of some research on science-policy collaborations around sustainability transitions (e.g., Lang et al. 2012). Scientists also uniquely implemented incremental solutions that were targeted at improving existing technologies and policies related to water sustainability. That said, the science stakeholders participating in the shadow network we studied were largely drawn from a few fields, particularly economics and physical geography, that tend toward more conservative approaches to social change. It is possible that the inclusion of scientists and scholars representing fields more aligned with radical change, such as radical geography, engaged anthropology, women's and ethnic studies, or science and technology studies, would have produced different outcomes.

Our study had a number of limitations that cause us to interpret our findings with caution. First, the composition of the shadow network we studied was formed organically and not experimentally controlled (as is nearly always the case with shadow networks). This process resulted in the exclusion of potentially interesting stakeholders, e.g., from the civil society sector and scholars with more radically innovative research agendas. Second, because of difficulties in systematically tracking informal and unplanned interactions among shadow network members, we were only able to systematically analyze stakeholder roles and social influence in the context of the group meetings. Clearly, meaningful shadow network interactions also happen outside of meeting contexts, and future ethnographic research could examine this. Third, our data in Table 3 are based on stakeholders' verbal accounts of the innovations that they have implemented in their respective cities; as such, we cannot use these data to independently evaluate or verify the efficacy or impact of their specific innovations. Fourth, our work focuses on sustainability transitions around urban water management, and does not fully address important linked sectors (such as the economy). A final caution is that our work focuses only on social influence around support for radical innovations; much of the important work of shadow networks in sustainability transitions lies beyond the confines of our analysis, including changing regulations, gaining public support, addressing subsidies and pricing, and eliminating other structural barriers to the 
propagation of niche practices. Future work should examine how dynamics of support and social influence in shadow networks are linked to actions in support of radical innovations and niche practices.

In sum, our work demonstrates the role and dynamics of shadow networks in sustainability transitions. Focused analysis of stakeholder roles and social influences may help illuminate how radical innovations move from niche to regime. Our findings contribute to the wider literature on stakeholder dynamics, social influence, and sustainability transitions, and point to the need for more focused research on the microdynamics of shadow networks.

Responses to this article can be read online at: http://www.ecologyandsociety.org/issues/responses. php/11451

\section{Acknowledgments:}

This material is based upon work supported by the National Science Foundation under Grant No. SES-1462086, DMUU: DCDC III: Transformational Solutions for Urban Water Sustainability Transitions in the Colorado River Basin. Wutich and Bausch also received support from the U.S. Department of Agriculture (USDA2017-68007-26584, no. 1013079). We also thank Ray Quay for his help on the project. Any opinions, findings, and conclusions or recommendation expressed in this material are those of the author (s) and do not necessarily reflect the views of the NSF or USDA. This study received ethical approval under IRB\#STUDY00002766 at the Office of Research Integrity and Assurance of Arizona State University.

\section{LITERATURE CITED}

Ault, T. R., J. S. Mankin, B. I. Cook, and J. E. Smerdon. 2016. Relative impacts of mitigation, temperature, and precipitation on 21st-century megadrought risk in the American Southwest. Science Advances 2(10):e1600873. https://doi.org/10.1126/ sciadv. 1600873

Avelino, F., and J. Grin. 2017. Beyond deconstruction. A reconstructive perspective on sustainability transition governance. Environmental Innovation and Societal Transitions 22:15-25. https://doi.org/10.1016/j.eist.2016.07.003

Avelino, F., and J. M. Wittmayer. 2016. Shifting power relations in sustainability transitions: a multi-actor perspective. Journal of Environmental Policy \& Planning 18(5):628-649. https://doi. org/10.1080/1523908X.2015.1112259

Bernard, H. R., A. Wutich, and G. W. Ryan. 2016. Analyzing qualitative data: systematic approaches. SAGE, Thousand Oaks, California, USA.

Boons, F., C. Montalvo, J. Quist, and M. Wagner. 2013. Sustainable innovation, business models and economic performance: an overview. Journal of Cleaner Production 45:1-8. https://doi.org/10.1016/j.jclepro.2012.08.013
Bos, J. J., and R. R. Brown. 2012. Governance experimentation and factors of success in socio-technical transitions in the urban water sector. Technological Forecasting and Social Change 79:1340-1353. https://doi.org/10.1016/j.techfore.2012.04.006

Bos, J. J., R. R. Brown, R. R., and M. A. Farrelly. 2015. Building networks and coalitions to promote transformational change: insights from an Australian urban water planning case study. Environmental Innovation and Societal Transitions 15:11-25. https://doi.org/10.1016/j.eist.2014.10.002

Brown, R. R., M. A. Farrelly, and D. A. Loorbach. 2013. Actors working the institutions in sustainability transitions: the case of Melbourne's stormwater management. Global Environmental Change 23(4):701-718. https://doi.org/10.1016/j.gloenvcha.2013.02.013

Brown, R., B. Rogers, and L. Werbeloff. 2016. Moving toward water sensitive cities: a guidance manual for strategists and policy makers. Cooperative Research Centres for Water Sensitive Cities, Melbourne, Australia. [online] URL: https://watersensitivecities. org.au/wp-content/uploads/2016/05/TMR_A4-1_MovingTowardWSC. pdf

Brundiers, K., and H. C. Eakin. 2018. Leveraging post-disaster windows of opportunities for change towards sustainability: a framework. Sustainability 10(5):1390. https://doi.org/10.3390/ $\underline{\text { su10051390 }}$

Christensen, N. S., A. W. Wood, N. Voisin, D. Lettenmaier, and R. N. Palmer. 2004. The effects of climate change on the hydrology and water resources of the Colorado River basin. Climatic Change 62:337-363. https://doi.org/10.1023/B:CLIM.0000013684.13621.1f

Cook, B. I., T. R. Ault, and J. E. Smerdon. 2015. Unprecedented 21 st century drought risk in the American Southwest and Central Plains. Science Advances 1(1):e1400082. https://doi.org/10.1126/ sciadv. 1400082

de Haan, F. J., B. C. Rogers, N. Frantzeskaki, and R. R. Brown. 2015. Transitions through a lens of urban water. Environmental Innovation and Societal Transitions 15:1-10. https://doi. org/10.1016/j.eist.2014.11.005

de Haan, F. J., and J. Rotmans. 2018. A proposed theoretical framework for actors in transformative change. Technological Forecasting and Social Change 128:275-286. https://doi. org/10.1016/j.techfore.2017.12.017

Elzen, B., and A. Wieczorek. 2005. Transitions towards sustainability through system innovation. Technological Forecasting and Social Change 72:651-661. https://doi. org/10.1016/j.techfore.2005.04.002

Farla, J., J. Markard, R. Raven, and L. Coenen. 2012. Sustainability transitions in the making: a closer look at actors, strategies and resources. Technological Forecasting and Social Change 79:991-998. https://doi.org/10.1016/j.techfore.2012.02.001

Fischer, L.-B., and J. Newig. 2016. Importance of actors and agency in sustainability transitions: a systematic exploration of the literature. Sustainability 8(5):476. https://doi.org/10.3390/ $\underline{\text { su} 8050476}$

Forman, J., and L. Damschroder. 2007. Qualitative content analysis. Pages 39-62 in L. Jacoby and L. Siminoff, editors. Empirical methods for bioethics: a primer. Emerald Group, Bingley, UK. https://doi.org/10.1016/S1479-3709(07)11003-7 
Foxon, T. J., G. P. Hammond, and P. J. Pearson. 2010. Developing transition pathways for a low carbon electricity system in the UK. Technological Forecasting and Social Change 77(8):1203-1213. https://doi.org/10.1016/j.techfore.2010.04.002

Geels, F. W. 2002. Technological transitions as evolutionary reconfiguration processes: a multi-level perspective and a casestudy. Research Policy 31(8-9):1257-1274. https://doi.org/10.1016/ $\underline{\mathrm{S} 0048-7333(02) 00062-8}$

Geels, F. W. 2012. A socio-technical analysis of low-carbon transitions: introducing the multi-level perspective into transport studies. Journal of Transport Geography 24:471-482. https://doi. org/10.1016/j.jtrangeo.2012.01.021

Gelcich, S., T. P. Hughes, P. Olsson, C. Folke, O. Defeo, M. Fernández, S. Foale, L. H. Gunderson, C. Rodríguez-Sickert, M. Scheffer, R. S. Steneck, and J. C. Castilla. 2010. Navigating transformations in governance of Chilean marine coastal resources. Proceedings of the National Academy of Sciences 107 (39):16794-16799. https://doi.org/10.1073/pnas.1012021107

Gober, P. 2013. Getting outside the water box: the need for new approaches to water planning and policy. Water Resources Management 27:955-957. https://doi.org/10.1007/s11269-012-0222y

Gober, P. 2018. Building resilience for uncertain water futures. Palgrave Macmillan, Cham, Switzerland. https://doi. org/10.1007/978-3-319-71234-5

Gonzalez, P., G. M. Garfin, D. D. Breshears, K. M. Brooks, H. E. Brown, E. H. Elias, A. Gunasekara, N. Huntly, J. K. Maldonado, N. J. Mantua, H. G. Margolis, S. McAfee, B. R. Middleton, B. H. Udall. 2018. Southwest. Pages 1101-1184 in D. R. Reidmiller, C. W. Avery, D. R. Easterling, K. E. Kunkel, K. L. M. Lewis, T. K. Maycock, B. C. Stewart, editors. Impacts, risks, and adaptation in the United States: Fourth National Climate Assessment, Volume II. U.S. Global Change Research, Washington, D.C., USA. https://doi.org/10.1002/essoar.10500376.1

Grin, J., J. Rotmans, and J. Schot. 2010. Transitions to sustainable development: new directions in the study of long term transformative change. Routledge, New York, New York, USA. https://doi.org/10.4324/9780203856598

Guest, G., A. Bunce, and L. Johnson. 2006. How many interviews are enough? An experiment with data saturation and variability. Field Methods 18(1):59-82. https://doi.org/10.1177/1525822x05279903

Guest, G., E. Namey, and K. McKenna. 2017. How many focus groups are enough? Building an evidence base for nonprobability sample sizes. Field Methods 29(1):3-22. https://doi.

org/10.1177/1525822X16639015

Gunderson, L. 1999. Resilience, flexibility and adaptive management -- antidotes for spurious certitude? Conservation Ecology 3(1):7. https://doi.org/10.5751/ES-00089-030107

Hundley, N. 2009. Water and the West: the Colorado River compact and the politics of water in the American West. University of California Press, Berkeley, California, USA.

Kates, R. W., W. R. Travis, and T. J. Wilbanks. 2012. Transformational adaptation when incremental adaptations to climate change are insufficient. Proceedings of the National
Academy of Sciences 109(19):7156-7161. https://doi.org/10.1073/ pnas. 1115521109

Lang, D. J., A. Wiek, M. Bergmann, M. Stauffacher, P. Martens, P. Moll, M. Swilling, and C. J. Thomas. 2012. Transdisciplinary research in sustainability science: practice, principles, and challenges. Sustainability Science 7:25-43. https://doi.org/10.1007/ s11625-011-0149-X

Larson, K. L., A. Wiek, and L. W. Keeler. 2013. A comprehensive sustainability appraisal of water governance in Phoenix, AZ. Journal of Environmental Management 116:58-71. https://doi. org/10.1016/j.jenvman.2012.11.016

Loorbach, D. 2010. Transition management for sustainable development: a prescriptive, complexity-based governance framework. Governance: An International Journal of Policy, Administration, and Institutions 23(1):161-183. https://doi. org/10.1111/j.1468-0491.2009.01471.x

Loorbach, D., N. Frantzeskaki, and F. Avelino. 2017. Sustainability transitions research: transforming science and practice for societal change. Annual Review of Environment and Resources 42:599-626. https://doi.org/10.1146/annurevenviron-102014-021340

Markard, J., R. Raven, and B. Truffer. 2012. Sustainability transitions: an emerging field of research and its prospects. Research Policy 41(6):955-967. https://doi.org/10.1016/j. respol.2012.02.013

Olsson, P., V. Galaz, and W. J. Boonstra. 2014. Sustainability transformations: a resilience perspective. Ecology and Society 19 (4):1. https://doi.org/10.5751/ES-06799-190401

Olsson, P., L. H. Gunderson, S. R. Carpenter, P. Ryan, L. Lebel, C. Folke, and C. S. Holling. 2006. Shooting the rapids: navigating transitions to adaptive governance of social-ecological systems. Ecology and Society 11(1):18. https://doi.org/10.5751/ES-01595-110118

Pahl-Wostl, C. 2009. A conceptual framework for analysing adaptive capacity and multi-level learning processes in resource governance regimes. Global Environmental Change 19(3):354-365. https://doi.org/10.1016/j.gloenvcha.2009.06.001

Pelling, M. 2010. Adaptation to climate change: from resilience to transformation. Routledge, London, UK. https://doi. org/10.4324/9780203889046

Pelling, M., C. High, J. Dearing, and D. Smith. 2008. Shadow spaces for social learning: a relational understanding of adaptive capacity to climate change within organisations. Environment and Planning A: Economy and Space 40(4):867-884. https://doi. org/10.1068/a39148

Quay, R., K. L. Larson, and D. D. White. 2013. Enhancing water sustainability through university-policy collaborations: experiences and lessons from researchers and decision-makers. Water Resources IMPACT 15(2):17-19.

Quay, R., K. Larson, D. White, and C. Hester. 2017. Urban landscape water use research. Project 4633. The Water Research Foundation, Alexandria, Virginia, USA.

Rock, M., J. T. Murphy, R. Rasiah, P. van Seters, and S. Managi. 2009. A hard slog, not a leap frog: globalization and sustainability 
transitions in developing Asia. Technological Forecasting and Social Change 76(2):241-254. https://doi.org/10.1016/j. techfore.2007.11.014

Rotmans, J., R. Kemp, and M. van Asselt. 2001. More evolution than revolution: transition management in public policy. Foresight 3(1):15-31. https://doi.org/10.1108/14636680110803003

Sullivan, A., D. D. White, and M. Hanemann. 2019. Designing collaborative governance: insights from the drought contingency planning process for the lower Colorado River basin. Environmental Science \& Policy 91:39-49. https://doi.org/10.1016/ j.envsci.2018.10.011

Sullivan, A., D. D. White, K. L. Larson, and A. Wutich. 2017. Towards water sensitive cities in the Colorado River Basin: a comparative historical analysis to inform future urban water sustainability transitions. Sustainability 9(5):761. https://doi. org/10.3390/su9050761

Taylor, M. 2014. The political ecology of climate change adaptation: livelihoods, agrarian change and the conflicts of development. Routledge, London, UK. https://doi. org/10.4324/9780203762486

U.S. Bureau of Reclamation (USBOR). 2018. Another dry year in the Colorado River Basin increases the need for additional state and federal actions. U.S. Bureau of Reclamation, Denver, Colorado, USA. [online] URL: https://www.usbr.gov/newsroom/ newsrelease/detail.cfm?RecordID $=62170$

Westley, F. R., P. Olsson, C. Folke, T. Homer-Dixon, H. Vredenburg, D. Loorbach, J. Thompson, M. Nilsson, E. Lambin, J. Sendzimir, B. Banerjee, V. Galaz, and S. van der Leeuw. 2011. Tipping Toward sustainability: emerging pathways of transformation. Ambio 40:762. https://doi.org/10.1007/s13280-011-0186-9

Westley, F. R., O. Tjornbo, L. Schultz, P. Olsson, C. Folke, B. Crona, and O. Bodin. 2013. A theory of transformative agency in linked social-ecological systems. Ecology and Society 18(3):27. https://doi.org/10.5751/ES-05072-180327

White, D. D., E. K. Rauh, A. Sullivan, K. Larson, A. Wutich, D. Linthicum, V. Horvath, and K. L. Lawless. 2019. Public attitudes toward urban water sustainability transitions: a multi-city survey in the western United States. Sustainability Science 14:1469-1483. https://doi.org/10.1007/s11625-019-00658-Z

Wittmayer, J. M., F. Avelino, F. van Steenbergen, and D. Loorbach. 2017. Actor roles in transition: insights from sociological perspectives. Environmental Innovation and Societal Transitions 24:45-56. https://doi.org/10.1016/j.eist.2016.10.003

Woodhouse, C. A., D. M. Meko, G. M. MacDonald, D. W. Stahle, and E. R. Cook. 2010. A 1,200-year perspective of 21st century drought in southwestern North America. Proceedings of the National Academy of Sciences 107(50):21283-21288. https://doi. org/10.1073/pnas.0911197107 